\title{
Guest Editors' Note
}

\author{
D. C. Haworth · Z. Warhaft
}

Received: 20 September 2010 / Accepted: 20 September 2010 / Published online: 28 September 2010

(C) Springer Science+Business Media B.V. 2010

It has been a pleasure and an honor to serve as the Guest Editors for this Special Issue of Flow, Turbulence and Combustion that is being published in celebration of Steve Pope's 60th birthday. We are delighted with the enthusiastic response to our invitation to submit manuscripts. It has resulted in high quality papers filling two full issues of the journal, surely a reflection of the esteem felt for Steve by his colleagues. The contributions include experimental, theoretical and computational studies in nonreacting and reacting flows from multiple research groups around the world. Contributors include several of Steve's former students and postdocs, current and former collaborators, and others who have been influenced by his work.

We thank the authors and the reviewers for their timely responses to the call for papers and the invitations to review manuscripts, respectively. This has allowed this special issue to be published within one year of the actual date of Steve's 60th birthday.

Submitted for the Special Issue dedicated to S.B. Pope.

D. C. Haworth $(\varangle)$

The Pennsylvania State University, University Park, PA, USA

e-mail: dch12@psu.edu

Z. Warhaft

Cornell University, Ithaca, NY, USA

e-mail: zw16@cornell.edu 